
History Research

Reseña

\section{Raúl Molina Recio (dir.). Pioneros. Empresas y empresa- rios en el primer tercio del siglo xx en España. Granada, Editorial Comares, 2019, 345 pp. ISBN: 9788490458990.}

Editado por Raúl Molina Recio, esta monografía reúne las contribuciones de un nutrido grupo de investigadores que repasan la trayectoria económica y empresarial de una España que, a lo largo del primer tercio del siglo xx, aceleraba su ritmo de crecimiento y acortaba distancias con los países de su entorno. Así, este libro da cuenta de la labor pionera de un conjunto de empresarios que desarrollaron negocios en sectores muy diversos, dando nacimiento a una gestión empresarial cada vez más moderna, e implantando en nuestro país las tecnologías propias de la segunda industrialización. La monografía toma como unidad de análisis el binomio empresas-empresario, y pone especial énfasis en el impacto económico que las actividades empresariales tuvieron sobre la economía nacional, dejando más de lado el análisis exhaustivo del conjunto de los actores de la generación del primer tercio de siglo. Todos los trabajos incluidos en el libro proceden de comunicaciones presentadas en un coloquio científico celebrado en la Facultad de Ciencias Económicas y Empresariales de la Universidad de Extremadura, en mayo de 2019.

La obra está dividida en tres partes, bien definidas, que guardan entre sí una clara conexión y permiten que el lector avance desde lo general a lo específico, desde la globalidad del contexto económico y empresarial a la particularidad del caso. Tras una introducción a cargo del editor, la primera sección está dedicada al estudio del contexto histórico. Esta parte recoge la ponencia del profesor Gabriel Tortella, que analiza de forma minuciosa la trayectoria de España durante el primer tercio del siglo xx, abordando sus dimensiones macroeconómicas, de política económica, sociales, educativas, demográficas y sectoriales. Resulta de la misma especialmente interesante el argumento de cómo el progreso económico y las mejoras en los niveles de bienestar constituyen, frecuentemente, la antesala de procesos revolucionarios y, en nuestro país, de un conflicto fratricida que puso fin a casi cuatro decenios de crecimiento económico sólido y sostenido, iniciado en 1898.

La segunda parte del libro acerca su foco al contexto empresarial de la época e incluye dos capítulos. El primero, a cargo de Juan Antonio Rubio, Josean Garrués y Luis Chirosa, analiza la configuración y el perfil del poder corporativo español que dio lugar a un modelo de capitalismo clientelar en el que las redes personales y el poder político orientaron las actuaciones empresariales anteponiendo, en muchas ocasiones, los intereses particulares a los del conjunto de la población. En el segundo capítulo, Gloria Quiroga y Gabriel Tortella indagan en el perfil del gran empresariado español a partir de una muestra amplísima de 217 empresarios con actividad durante el primer tercio del siglo $\mathrm{xx}$, incluyendo su nivel educativo, sus principales sectores de actividad, sus incursiones políticas o su nivel y patrón de asociacionismo. Este perfil empresarial español se analiza con una lente comparativa, en relación con los homólogos franceses, ingleses y escoceses, alcanzando en conjunto una muestra de más de un millar de hombres de negocios. El estudio confirma el carácter pionero de la generación de empresarios españoles, en su sentido emprendedor, aunque también identifica en ella ciertas debilidades, en especial su escasa educación técnica, lo que lastraría la capacidad de innovación y el desarrollo tecnológico.

El libro presenta, en su tercera sección, los estudios de caso de empresarios y empresas selectos que constituyen el grueso de la obra, con nueve capítulos. Son casos específicos que, si bien no agotan el conjunto de los principales actores ni el total de sectores económicos, sí conforman una muestra representativa de la riqueza emprendedora y el carácter pionero de la generación empresarial de la época. Manuel Peña y Francisco Contreras abren la sección con un capítulo dedicado a la génesis del sector petrolero español, que se estudia a través de los casos de CEPSA y CAMPSA, y de la figura de Demetrio Carceller Segura, un polifacético empresario, hombre hecho a sí mismo, que fue pieza clave en la fundación de ambas. Raúl Molina aborda el caso de Damià Mateu i Blisa y de la empresa que fundó y presidió hasta su muerte en 1935, la Hispano-Suiza, Fábrica de Automóviles. A este capítulo le sigue el de Enrique Montañés, centrado en la industria agroalimentaria, en concreto de la producción y comercialización del jerez, con el caso de la empresa González Byass. El sector ferroviario se aborda en el capítulo a cargo de Gregorio Núñez, que analiza el desarrollo de la obra empresarial de Nicolás Escoriaza y Fabro y de su familia. El caso de la mítica Hispano-Suiza se retoma en un capítulo a cargo de Santiago López y Álvaro González, esta vez atendiendo a su actuación, especialmente puntera en tecnología, en el sector aeronáutico. Pablo Díaz Morlán aborda la industria naval y armamentística y el papel del empresario Horacio Echevarrieta en el contexto de las relaciones hispano-alemanas durante el periodo de entreguerras. La figura del empresario Ernesto Anastasio Pascual, también vinculado al sector naval, y su presencia en un elevado número de compañías, como Transmediterránea y Unión Naval de Levante ente otras muchas, se estudia detalladamente en el capítulo de Juan Zamora. José Peral-López y Celia López-Bravo se centran en la industria de la construcción y analizan una de sus figuras más representativas, José Entrecanales Ibarra, y su empresa Entrecanales y Távora. Finalmente, Andrés Sánchez Picón aborda el sector de la minería del oro a través del estudio de caso de la empresa Minas de Rodalquilar y el entramado de redes que la conectaron con otros actores clave en la época, como la Sociedad Española de Construcción Naval y el Banco de Vizcaya. 
En su conjunto, las contribuciones de esta última parte del libro ponen de relieve líneas comunes y relevantes: por una parte, que la empresa y el empresario fueron agentes activos y protagonistas de la modernización económica de España durante el primer tercio del siglo pasado, en tanto que actuaron como canales para la implantación de la técnica y la tecnología de la segunda industrialización. Por otra parte, que la labor empresarial se desarrolló dentro de un conjunto de vínculos que tejieron una amplia red, en la que se entremezclaron intereses empresariales, individuales o políticos.

En conclusión, el libro es de lectura fácil y amena, y constituye una contribución de gran interés para historiadores no solo económicos y de la empresa, sino también para estudiosos de disciplinas afines y lectores de cualquier perfil interesados en descubrir los cimientos empresariales de la economía española en un periodo clave. En mi opinión, la gran fortaleza del libro es que inserta la particularidad de la labor empresarial en la generalidad de los resultados macroeconómicos y nos invita a reflexionar sobre la conveniencia de desentrañar las fotos macro para descubrir a los personajes y las organizaciones de cuya labor dependen, en buena medida, los resultados agregados.

Águeda Gil-López Universidad Francisco de Vitoria 